ECONOMía TeORÍA y PrÁCtica • Nueva Época, número 47, julio-diciembre 2017,

pp. 9-30, http://dx.doi.org/10.24275/ETYPUAM/NE/472017/Antonelli

\title{
The Engines of the Creative Response: Reactivity and Knowledge Governance*
}

\section{Los motores de la respuesta creativa: la reactividad y la gobernanza del conocimiento}

\author{
Cristiano Antonelli**
}

\begin{abstract}
The notion of endogenous innovation as the outcome of the creative response of firms to out-of-equilibrium conditions is the cornerstone of the new evolutionary complexity. This essay explores the role of the reactivity of firms to out-of-equilibrium conditions and of knowledge governance in assessing the chances that creative responses actually take place as an alternative to adaptive responses. It implements a systemic frame able to show that: i) the levels of reactivity of firms enhance the research efforts of rims that try and cope with out-of-equilibrium conditions; ii) the actual rates of introduction of innovations and increase of total factor productivity are contingent upon the quality of knowledge governance, and iii) out-of-equilibrium conditions, as well as the amount of knowledge externalities are the endogenous outcome of the creative response.
\end{abstract}

Keywords: Creative response; Endogenous innovation; Reactivity; Knowledge externalities; Knowledge governance mechanisms.

JEL Codes: O33

\section{RESUMEN}

La noción de innovación endógena como producto de la respuesta creativa de las firmas en condiciones fuera del equilibrio es la piedra angular de la nueva complejidad evolucionista. Este ensayo explora el papel de la reacción de las firmas en condiciones fuera del equilibrio y de la gobernanza del conocimiento, estableciendo que las posibilidades de las respuestas creativas actualmente tienen lugar como una alternativa a las respuestas adaptativas. Se implementa un marco sistémico capaz de mostrar que: i) la calidad de la gobernanza del conocimiento es determinante para lograr la respuesta creativa de las firmas en lugar que la adaptativa y ii) los niveles de reacción de las firmas se enlazan a las tasas de introducción de innovaciones e incrementan la productividad total de los factores.

Palabras clave: respuesta creativa; innovación endógena; reacción; externalidades de conocimiento; mecanismos de gobernanza del conocimiento.

Clasificación JEL: O33

* The comments and suggestions of two anonymous referees are gratefully acknowledged.

** Dipartimento di Economia e Statistica, Università di Torino and BRICK (Bureau of Research in Innovation Complexity and Knowledge), Collegio Carlo Alberto. Email: cristiano.antonelli@, unito.it. ORCID: 0000-0002-5652-0510. 


\section{INTRODUCTION}

The Schumpeterian notion of creative response provides a consistent framework into which it is possible to articulate a comprehensive and coherent account of the endogenous determinants of the introduction of innovations. Firms caught in out-of-equilibrium conditions try and react to unexpected conditions of product and factor markets and hence levels of profitability and performances away from normal ones. Their reaction can be either adaptive or creative. When adaptive responses prevail firms can only change their techniques in the existing map of isoquants: the system converge to equilibrium. When their response is creative firms can actually introduce new technologies that change the existing map of isoquants. The chances the reaction is creative and the introduction of innovations successful, is contingent upon the amount of knowledge externalities the system, into which the firms are embedded, is able to provide. The availability of external knowledge at costs below equilibrium levels supports their creative response and makes the introduction of productivity increasing innovations possible. The introduction of innovations feed further out-of-equilibrium conditions that in turn push firms towards creative responses that may succeed again with the eventual introduction of new innovations provided the dynamics has not deteriorated the quality of knowledge governance mechanisms. In this case the system enters a positive loop of feedbacks where all the components -out-of-equilibrium conditions, knowledge generation, knowledge governance and innovation- are endogenous. The tools of evolutionary complexity apply.

When the system is not able to provide the access at low costs to knowledge spillovers, the response of firms is doomed to be adaptive. When the system does not provide the necessary access at low costs to the stock of quasi-public knowledge, firms can try and change their techniques, rather than their technologies: the system gravitates around equilibrium conditions without growth and change. The tools of equilibrium economics apply.

When the response of firms to out-of-equilibrium conditions is creative and strong, and the system supports it with persistent knowledge externalities that provide access to the stock of the existing quasi-public knowledge at low costs, the system is able to foster the rate of technological change and reproduce out-of-equilibrium conditions that may last until the quality of knowledge governance mechanisms stays put.

The dynamics of the innovation process is fully endogenous to the system and exhibits the typical characteristics of an emergent system property (Arthur, 2007, 2009, 20115; Foster and Metcalfe, 2012). The successful introduction of innovation in fact is the result of the interaction between individual action and the properties of the system (Antonelli, 2008, 2011, 2015a, 2017). 
This essay contributes the framework outlined so far with the analysis of the role of the levels of: i) the levels of reactivity of firms to out-of-equilibrium conditions; ii) the quality of knowledge governance mechanisms at work within economic systems that define the actual amount of knowledge externalities available to reactive firms, in assessing the rate of technological change.

In the rest of the essay, section 2 explores the evolutionary complexity of the interaction between endogenous out-of-equilibrium conditions, creative response and knowledge externalities that can be elaborated upon the foundations laid down by the Schumpeterian essay The creative response in economic history. Section 3 analyzes the relationship between out-of-equilibrium conditions and the response of firms focusing attention of the role of the levels of reactivity of firms. Section 4 recalls the role of knowledge externalities in making the creative response possible and effective focusing attention on the endogenous dynamics of knowledge governance mechanisms. Section 5 presents a simple model that enables to explore the systemic and endogenous dynamics of the creative response. The conclusions summarize the results of the analysis and explore their implications for both economic and policy analysis.

\section{THE EVOLUTIONARY COMPLEXITY OF ENDOGENOUS INNOVATION}

In the essay The creative response in economic history, published in the Journal of Economic History in 1947, Schumpeter provides a synthesis of the alternative views about the relationship between performances and innovation presented respectively in 1939 with Business Cycles and in 1942 with Capitalism Socialism and Democracy (Antonelli, 2008, 2015a and 2017).

In Business Cycles Schumpeter elaborates the view that firms are induced to introduce innovations to cope with the decline of their performances. His historic analysis of the innovation flows shows that the introduction of innovations peaks in the years of depression that follow the exhaustion of the opportunities provided by the previous gales of innovations. Firms are exposed to a decline of their performances: the growth of output is weak, profitability falls below the average, ultimately even actual losses emerge. The survival of firms is actually engendered. The introduction of innovations is regarded as a necessity to contrast the fall of performances below the average and possible risks of failure and exit. The generalized conditions of declining performances shared by many firms induce a collective innovation process that eventually leads to the emergence of new gales characterized by the complementarity and interoperability of a variety of new technologies. In Business Cycles Schumpeter elaborates the "failure inducement" mechanism, eventually articulated by Nelson and Winter (1982), according to which innovations are 
more likely to be introduced where profits and performances are below equilibrium and/or average levels.

A few years later, Schumpeter, with Capitalism Socialism and Democracy, provides an alternative framework where the relationship between performances and innovation is reversed. Firms that enjoy extra-profits are more likely to engage in the risky undertakings such as research and development activities that are at the origin of the possible introduction of innovations. Firms with profits and performances above the average, and above equilibrium levels, are more likely to introduce innovations also because they can fund with internal financial resources, the necessary research expenses. Profits above equilibrium reduce the levels of risk aversion and the liquidity constraints. Schumpeter, with Capitalism Socialism and Democracy, laid down the foundations of the well-known Schumpeterian hypothesis according to which the rates of innovation are faster in oligopolistic markets characterized by the rivalry among large corporations with performances well above equilibrium levels.

The analysis of Capitalism Socialism and Democracy contrasts the analysis of Business Cycles. Although the focus and the level of the analysis differs: the former elaborates at the aggregate level and focuses on the working of the system, the latter is typically microeconomic and impinges upon the theory of the firm, the relationship between performance and innovation is negative in the former and positive in the latter. The 1947 essay The creative response in economic history seems to provide a synthesis: firms try and innovate when they try and cope with out-of-equilibrium conditions. In turn out-of-equilibrium conditions take place both when performances are below and above equilibrium levels.

The intuition of The creative response in economic history enables to implement four important contributions that synthetize the different strands of literature that impinge upon the separate readership of the Schumpeterian legacy: $i$ ) it introduces the reactivity function whereby innovation takes place as a response to out-of-equilibrium conditions that can be both negative-as in Business Cycles-and positive as in Capitalism Socialism and Democracy; ii) it enables to operationalize the notion of procedural rationality; iii) it stresses the crucial role of the context into which the response takes place: $i v$ ) it provides the framework to grasp the endogenous relationship between out-of-equilibrium conditions and innovation. Let us consider them in turn.

The innovative response. The introduction by Schumpeter (1947) of the reactivity function can be regarded as a major contribution to economics. It encompasses and generalizes a variety of approaches: from the induced technological change approach to the demand pull and the oligopolistic rivalry, including the very basic notion of technical change of microeconomics as well as the evolutionary approach. 
In basic microeconomics firms "react" to changes in factor markets and in inputs costs, searching for new existing techniques on the "given" map of isoquants. The notion of reactive response finds here its foundations. The notion of innovative response can be regarded as a direct extension of the reactive technical change when technological change is no longer exogenous but is regarded as the endogenous outcome of firms conduct. In the demand pull approach, firms react to changes in the demand of their products enhancing the division of labor that enables to introduce innovations. In the induced technological change approach, firms react to changes in inputs costs and innovate, changing the map of -no longer given- isoquants. Since the seminal contribution of Dasgupta and Stiglitz (1980) decision making about R\&D activities of corporations is analyzed within the frame of the typical reaction function of oligopolistic rivalry. The evolutionary approach elaborated by Nelson and Winter (1982) assumes that firms change their routines when their performances fall below average levels: the attempt to innovate is viewed as a way to cope with emerging failures.

As a matter of fact the recent literature on the widespread surge of green technologies relies systematically on the notion of innovative reaction stressing the positive role of the upsurge of oil prices, carbon taxes and environmental constraints, as well as the strong increase of the demand for low-emission-production processes, capital goods and final products, as the determinants of the creative reaction of firms pushed to introduce new energy-saving and green technologies by unexpected out-of-equilibrium conditions (Porter and van der Linde, 1995; Newell, Jaffe, Stavins, 1999; Acemoglu et al., 2012; Aghion et al., 2016).

Yet this literature reveals three major limits: $i$ ) it fails to elaborate explicitly an integrated notion of innovative response that is able to frame into a single and comprehensive context that includes the different sources of out-of-equilibrium conditions, and $i i$ ) it portrays the relationship between out-of-equilibrium conditions and innovative response as automatic and deterministic as if all firms facing unexpected changes in their product and factor markets might actually innovate; iii) it assumes that the shocks to which firms react are exogenous and is not able to grasp their endogenous determinants.

The response as a form of procedural rationality. Schumpeterian decision-making is far from Olympian rationality. Firms make plans on the basis of their limited knowledge of the actual and expected conditions of product and factor markets. When their expectations fail, they try and elaborate responses that are highly contextual and constrained by sunk costs. The response is a form of procedural rationality. The Schumpeterian notion of creative/adaptive response complements and enriches the analysis of Herbert Simon about the intrinsic limits of knowledge and the role of bounded and procedural rationality $(1947,1979,1982)$. 
The role of externalities. The outcome of the Schumpeterian response is not deterministic but strictly conditional to the availability of knowledge externalities. The response of firms may be creative and leads to the actual introduction of innovations only if and when substantial knowledge externalities are available. When the quality of knowledge governance mechanisms and the size of the stock of quasi-public knowledge are low, the actual provision of knowledge externalities falls below critical values, the reactive attempt of firms fails to be innovative and the response is just adaptive: technical change substitutes technological change.

The response of firms to out-of-equilibrium changes in both their product and factor markets consists in mobilizing re-search activities. Such activities are necessary both to search for existing techniques that fit better with the changed conditions of product and factor markets and to introduce new technologies i.e. techniques that do not exist and do not belong to the existing map of isoquants. The search and identification of existing techniques, new to the firm but already known, is not free and entails specific search costs. In appropriate conditions determined by the properties of the system, that provide substantial knowledge externalities and hence the access to the stock of quasi-public knowledge at low costs, the research activities enable the generation of additional knowledge that may eventually lead to the introduction of new technologies. The differences in the outcome, whether it is just adaptive so as to consist in the identification of new viable techniques -among the many already available on the existing map of isoquants- or actually creative so as to enable the introduction of new technologies that reshape the map of isoquants, is determined by the amount of knowledge externalities available in the system and hence by the bottom line access and use costs of external knowledge (Antonelli, 2017).

The endogenous relationship between out-of-equilibrium conditions and innovation. The introduction of innovation as the outcome of the creative response of firms to out-of-equilibrium conditions, contingent upon the quality of knowledge externalities available in the system, is itself the cause of further out-of-equilibrium conditions. Out-of-equilibrium conditions are not the result of exogenous shocks, but the endogenous consequence of the innovative response of firms. Not only out-of-equilibrium conditions are endogenous to the system, but also the quality of knowledge externalities is determined within the system and may increase as well as decrease. The response of firms to out-of-equilibrium conditions, in fact, consists in the generation of additional technological knowledge that is necessary to introduce innovations. The additional knowledge spills in the system and affects the size and the quality of the stock of quasi-public knowledge available for the generation of new technological knowledge. At the same time the levels of access costs to the stock of quasi-public knowledge are determined by the systems of knowledge interactions and transactions between firms and other knowledge-intensive agents. 


\section{LEVELS OF REACTIVITY AND RESEARCH EFFORTS}

It seems now useful to make a step forward analyzing the crucial role of the levels of reactivity of firms that try and cope with out-of-equilibrium conditions. Decision-making is based upon procedural rationality: on one hand firms do not command the understanding of all the possible alternatives, on the other they are able to explore unchartered waters and introduce innovations and change their routines. At each point in time they try and cope with the changing conditions of product and factor markets under the constraint of sunk costs and past decisions. Their capability to cope with the changing conditions of the economic environment is the outcome of a variety of factors including the types of structure and organization, the role of shareholders and stakeholders, the types of industrial relations and the levels of entrepreneurship of top managers. Figure 1 compares the amount of research efforts (R) on the vertical axis with the levels of performances both above and below the average (II). Figure 1 exhibits two alternative levels of reactivity. Around equilibrium levels, at the intersection of the two axes, firms do not try and change their production processes. Liquidity constraints and risk aversion restrain the amount of research efforts. The farther away from equilibrium levels, the stronger is the likelihood that firms try and change their production processes either by searching for new existing techniques or by actual research activities that, provided substantial knowledge externalities are available, may enable the introduction of new technologies.

Two mechanisms are at work in this process: $i$ ) the failure inducement articulated by Schumpeter in Business Cycle and ii) the success inducement analyzed by Schumpeter in Capitalism Socialism and Democracy. Let us consider them in turn. Firms try and innovate to cope with the high risks of failure in the right quadrant where the larger are the losses and the worst their performances and the stronger the efforts in research activities. The negative conditions of their performances and the high risks of failure reduce the risk aversion. The substitution of tangible investments with intangible ones and the increase in research activities is the last chance to try and cope with the threat of survival. In the left quadrant, instead, the larger are the profits and the better the performances and the stronger the efforts in research activities. Firms can fund a larger budget of research activities that may put them in the condition to try and innovate because of the abundance of internal cash. Large internal cash reduces the liquidity constraints and avoids the credit rationing of external finance. Large internal cash reduces the levels of risk. The possible failure of innovative undertaking does not put at risk the entrepreneurial managers that have already secured high levels of profitability for their shareholders and stakeholders. The success of the risky undertakings may yield further growth and larger profits that would benefit the entrepreneurial managers. 
The relationship, between out-of-equilibrium conditions however, can take place with different levels of elasticity. Figure 1 exhibits two different levels of reactivity. The bold line represents low levels of reactivity: firms are reluctant to change their levels of innovative efforts. The dotted line represents high levels of reactivity ${ }^{1}$.

The key point is that the extent to which the change in the levels of-relativeperformances affects the levels of research efforts. The bold line represents high levels of reactivity stemming from high levels entrepreneurship. Firms guided by managers with high levels of entrepreneurship are more likely to exhibit high levels of reactivity to the changing levels of profitability and performance at large. Firms guided by managers, with low levels of entrepreneurship, are less reactive.

Figure 1. Performances and research efforts: levels of reactivity

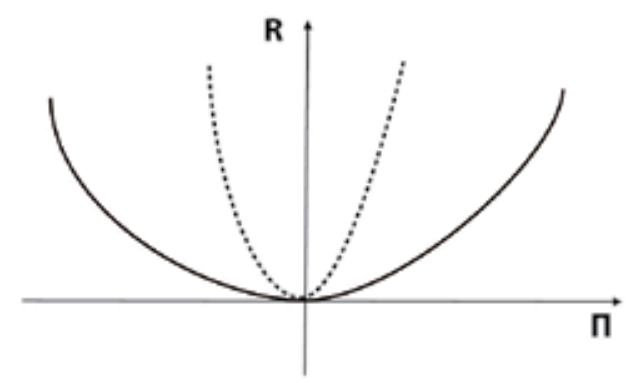

Figure 2 compares the levels of reactivity with the levels of research efforts: on the horizontal axis $\Delta \Pi$ measures in absolute terms the differences between the levels of profitability and performances of each firm and the normal and/or average profitability and performances of all the firms in the system and on the vertical axis $\mathrm{R}$ measures the levels of research efforts. The levels of reactivity play an important role in assessing the amount of research efforts that are made in order to cope with the out-of-equilibrium conditions. Large research budgets may

${ }^{1}$ In figure 1 the quadratic relationship is symmetric: the response of firms to performances above and below the average is shaped to be specular. Internal financial constraints and credit rationing might reduce the capability of firms with performances below the average -and even more below normal levels of profitability- to fund the necessary research activities. At the same time, however, firms with performance above the average may use part of their profits to pay higher dividends to shareholders, larger wages to employees and fund other benefits to stakeholders, reducing the amount of resources that can be used to fund internally R\&D activities. The actual shape of the quadratic relationship is determined by the institutional set-up of financial markets, intellectual property rights, industrial relations, product and factor markets. 
implement a creative response and introduce innovations when large knowledge externalities that reduce the access costs to the stock of quasi-public knowledge are made possible by the quality of knowledge governance mechanisms at work within the system.

Figure 2. Levels of reactivity and research efforts

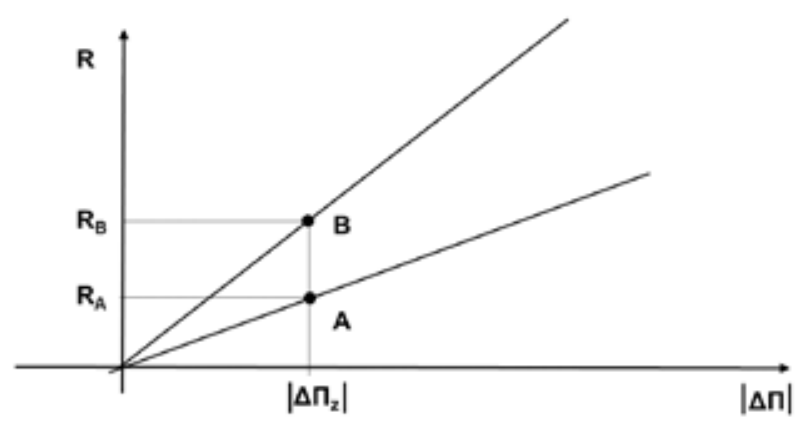

Figure 2 shows that the same level of out-of-equilibrium conditions measured by the difference in absolute terms between the levels of profitability and performances of each firm and the normal levels of profitability and performance $\left(\mathrm{DP}_{\mathrm{Z}}\right)$ there are two quite different levels of research efforts: $R_{A}$ with low levels or reactivity and $R_{B}$ with high levels of reactivity. The levels of reactivity play a major role in assessing the elasticity of the system to out-of-equilibrium conditions.

The implications of this analysis are important to assess the actual determinants of the innovative efforts of an economic system. The amount of research efforts is likely to be larger in systems characterized: i) not only by widespread out-of-equilibrium conditions than in systems where all firms operate near by equilibrium and the variance of profitability and performance at large is small, but also ii) by high rather than low levels of reactivity.

These implications can be amplified when we measure out-of-equilibrium conditions in terms of variance with respect to the average profitability and performances, rather than with respect to normal profitability and performances. When average profitability and performances is taken into account as the relevant measure of out-of-equilibrium conditions we expect that in systems with average profitability and performances above the normal levels but low levels of variance, the reactivity is always lower than in systems with where out-of-equilibrium conditions are measured with respect to normal profitability and performances. The larger the variance with respect to the average and the larger the chances that firms try and react. When the out-of-equilibrium conditions of each firm are refereed to average 
profitability and performances, it becomes immediately clear that the larger is the variety and heterogeneity of firms and the larger the innovative efforts. With larger research efforts, and given levels of knowledge externalities, there are larger chances of faster rates of introduction of innovation and increase of total factor productivity and ultimately economic growth.

The results of the replicator analysis, according to which the larger is the variety of firms and the larger are the rates of growth, are confirmed overcoming the darwinistic and exogenous assumptions of the replicator analysis (Metcalfe, 1998).

The replicator analysis, in fact, assumes the heterogeneity of firms in terms of given and exogenous, or randomly determined, differences in fitness among species competing for scarce resources in a given environment. The larger the variance in terms of levels of fitness and the larger the rates of growth simply because the eventual survival and the specie with larger fitness parameters and the exit of the less performing ones, leads to a larger population and faster rates of growth along the substitution process.

In the approach outlined far, instead, the larger is the variety and heterogeneity of firms and the larger are the research efforts that may eventually lead, with high levels of knowledge externalities provided by the system, to a faster rate of introduction (and creative adoption) of technological innovations and hence larger rates of increase of total factor productivity. The positive relationship between heterogeneity, variety, and variance of profitability, performances and rates of growth in confirmed. The determinants of the relationship, however, are completely different. In the standard replicator analysis, innovation is exogenous. Growth is determined by the diffusion of the exogenous innovation. In the analysis implemented so far, innovation is endogenous.

\section{THE LEVELS OF KNOWLEDGE GOVERNANCE AND THE CREATIVE RESPONSE}

The creative response of firms to out-of-equilibrium conditions is contingent upon the actual costs of knowledge. Knowledge costs are determined by the knowledge externalities available in the system. Knowledge externalities are pecuniary and diachronic. They make possible the use of knowledge spillovers at costs that are below the equilibrium levels of knowledge as a standard good. In turn the amount of knowledge externalities available in a system depends upon the quality of knowledge governance mechanisms at work in a system (Antonelli, 2017).

Knowledge governance consists in the structure of knowledge generation activities, the organization of the architecture of knowledge of interactions and transactions and the institutional set-up that makes the accumulation of the stock of 
quasi-public knowledge possible and enables the use of the stock of quasi-public knowledge at low costs (Ostrom and Hess, 2006).

Because of the limited appropriability of knowledge, inventors can retain the full control of the economic benefits, stemming from the new technological knowledge they have generated, only for a limited stretch of time. After that appropriation window, technological knowledge becomes a quasi-public good and contributes the accumulation of a stock of quasi-public knowledge that third parties can try and access to use it as an indispensable complementary input into the recombinant generation of further knowledge (Weitzman, 1996).

High quality knowledge governance mechanisms favor knowledge interactions along the vertical stages of the inter-sectorial division of labor with effective user-producer interactions that include also final markets, effective knowledge transmission between public and private research centers and reduce the exclusivity of intellectual property rights so as to support both the necessary rewards of knowledge producers and yet the widespread secondary sues of proprietary knowledge as an input into the recombinant generation of new knowledge (Antonelli, 2015b).

The quality of knowledge governance mechanisms at work in the system plays a central role in this process on two counts.

First, the actual accumulation of the knowledge spilling from 'inventors' into the stock of quasi-public knowledge is contingent upon the quality of the knowledge governance mechanisms. In systems with poor knowledge governance mechanisms the uncontrolled spillovers of knowledge dissipates in the atmosphere and results in slow rates of accumulation of the stock of quasi-public knowledge. On the opposite, knowledge spillovers add effectively to the existing stock of quasi-public knowledge in systems endowed with high quality knowledge governance mechanisms and low levels of dissipation.

Second, the access and use of knowledge spilling from third parties accumulated in the stock of quasi-public knowledge is not free. Relevant absorption costs are necessary in order to search, identify, decode, access and finally use-again- the knowledge available in the system. Knowledge absorption costs are reduced by effective knowledge governance mechanism that favor the search, screening and access to existing knowledge for new uses.

The actual levels of knowledge externalities and hence of the costs of external knowledge are determined by the size of the stock of quasi public knowledge and the amount of absorption activities that are necessary to benefit and use it. When high quality knowledge governance mechanisms are at work, firms can access external knowledge at low costs, far below equilibrium levels, both because of low absorption costs and the large size of the stock of quasi-public knowledge. Produc- 
tivity enhancing innovations depend upon the actual access to knowledge spillovers that make external knowledge, an indispensable input in the recombinant generation of new knowledge, available at costs that are below equilibrium levels.

In these systems, consequently, firms that try and cope with out-of-equilibrium conditions have larger chances to implement a creative response and introduce technological innovations that reshape the map of isoquants.

Firms embedded in systems with poor knowledge governance mechanisms experience high absorption costs of knowledge spillovers. The final costs of external knowledge are larger, actually close to the levels of knowledge costs it-it-were-a standard-economic-good. These firms cannot take advantage of knowledge externalities. Their response to emerging out-of-equilibrium conditions is consequently adaptive. They try and cope with out-of-equilibrium conditions by means of technical changes that enable them to move on the existing map of isoquants.

The introduction of productivity-increasing innovations is strictly contingent upon the properties of the system. For given levels of firms' reactivity, the response of firms is actually creative according to the amount of knowledge externalities available in the system and its success -in terms of actual introduction of productivity enhancing innovations-is ultimately determined by: i) the actual costs of the external knowledge that is an indispensable input strictly complementary to the research efforts in the recombinant generation of new knowledge and ii) the actual bottom-line costs of the knowledge that enters the technology production function as a complementary input next to the traditional tangible ones such as capital and labor..

Hence, for given levels of reactivity, a system and each agent within the system, has higher chances to select a creative, rather than adaptive response, to out-of-equilibrium conditions, according to the levels of access costs to the stock of quasi-public knowledge that in turn depends upon the quality of knowledge governance mechanisms at work in the system.

This result complements the outcome of the previous section according to which, for given levels of knowledge externalities, the larger are the levels of reactivity and the larger the research efforts and hence the rate of introduction of innovations.

The analysis makes also clear that the quality of knowledge governance mechanisms is fully endogenous: it is shaped and continuously re-shaped by the conduct of firms, by their levels of reactivity and by the actual rates of generation of new technological knowledge and eventual introduction of innovations. The quality of knowledge governance mechanisms may stay put through time, as well as improve and deteriorate. These processes are typically non-ergodic and yet far from deterministic: typically path rather than past dependent. 


\section{THE DYNAMICS OF THE CREATIVE RESPONSE: A GRAPHIC EXPOSITION}

The elements introduced so far to explore the role of the engines of the creative response can now be nested into a full fledged system of interdependence that relates the creative response to the levels of reactivity and hence of the actual amount of research efforts that take place in a system, the consequent amount of technological knowledge that can be generated taking into account he levels of knowledge externalities and consequently the extent to which the response is creative and its effects in terms of the rate of introduction of innovations and the amount of output and total factor productivity that can be achieved.

The I Quadrant of Figure 3 reproduces simply Figure 2. Starting with a given level of DП, the margin of actual profitability and performances with respect to normal (average) profitability, the first quadrant shows the effects of the different levels of reactivity. With high levels of reactivity, firms are induced to the innovative effort $\mathrm{R}_{2}$ clearly larger than $\mathrm{R}_{1}$ that would take place with low levels of reactivity.

The II Quadrant represents the working of the knowledge generation activities $^{2}$. Knowledge generation activities are far more productive when they can rely upon strong knowledge externalities that enable to access the stock of quasi-public knowledge at low costs. The innovative efforts yield a larger knowledge output (T): respectively found in F and $\mathrm{G}$ for more and less reactive firms. When knowledge externalities do not support the generation of technological knowledge, and the access costs to the stock of the quasi-public knowledge are close to the equilibrium levels of knowledge -i.e. as if it were a standard-economic good with high levels of exhaustibility and appropriability ${ }^{3}$ - the output is lower: respectively D and $\mathrm{C}$ for more and less reactive firms.

The III Quadrant shows the working of the production activities. Technological knowledge $(\mathrm{T})$ enters the production function as an input next to the traditional tangible inputs capital and labor. Assuming fixed levels of capital and labor, the III Quadrant shows the effects of the larger amount of technological knowledge generated in the

\footnotetext{
${ }^{2}$ The geometric representation posits contant returns to scale in knowledge generation activities. Diminishing returns to scale might be easily accomodated with a negative second derivative without altering the basic relationship.

${ }^{3}$ Arrow (1962) identifies the special features of knowledge such as limited appropriability and exhaustibility, substantial indivisibility, cumulability and complementarity, low costs of reproduction by confronting knowledge with respect to standard economic goods. The negative effects of the limited appropriability of knowledge on the incentives to its generation, with high quality levels of knowledge governance mechanisms and substantial levels of knowledge cumulability and indivisibility, can be more than compensated by their positive effects in terms of spillovers and the consequent reduction of the costs of knowledge below equilibrium levels.
} 
II Quadrant on the production of the output Y. For given levels of reactivity, when the amount of technological knowledge (T) is larger than in equilibrium because of the positive effects of knowledge externalities, output $\mathrm{Y}$ is larger than it would be when the amount of technological knowledge matches equilibrium levels. As the III quadrant shows when reactivity levels are high $\left(\mathrm{R}_{2}\right)$ and knowledge externalities are effective, knowledge output $\mathrm{T}_{\mathrm{F}}$ is larger than $\mathrm{T}_{\mathrm{D}}$ at the levels that take place when knowledge externalities do not support the generation of knowledge at costs that are below equilibrium levels. For the same token, when reactivity levels are low $\left(R_{1}\right)$ and knowledge externalities are effective, the knowledge output $T_{G}$ is larger than $T_{C}$ at the levels that take place when knowledge externalities do not support the generation of knowledge at costs that are below equilibrium levels. The distances on the inferior vertical axis $\left(\mathrm{T}_{\mathrm{G}} \mathrm{T}_{\mathrm{C}}\right)$ and $\left(\mathrm{T}_{\mathrm{F}} \mathrm{T}_{\mathrm{D}}\right)$ measure the effects of the lower costs of technological knowledge on the output $\mathrm{Y}$ and as such provide a reliable clue for the effects of knowledge externalities on total factor productivity.

It is clear that a system endowed with high levels of both the reactivity of firms and the quality of knowledge governance mechanisms is better able to increase its not only its rates of growth, but also and most importantly its rates of increase of its total factor productivity: $\left(\mathrm{T}_{\mathrm{G}} \mathrm{T}_{\mathrm{C}}\right)>\left(\mathrm{T}_{\mathrm{F}} \mathrm{T}_{\mathrm{D}}\right)$.

The levels of reactivity of firms to out-of-equilibrium conditions and the quality of knowledge governance mechanisms that defines the actual amount of knowledge externalities are the drivers of the creative response. The larger the reactivity of firms and the higher the quality of the knowledge governance mechanisms and the larger the rates of introduction of innovations, as measured by the amount of technological knowledge generated, and the growth of both output and total factor productivity.

The system of interdependencies framed in Figure 1 provides the building blocks that enable to explore the IV Quadrant and to study the dynamics of the system. It is in fact clear that:

1) the larger is the variance of profitability and performances levels and the higher the reactivity levels and the larger the amount of research efforts;

2 ) the larger the amount of research efforts and the lower the costs of accessing and using the stock of quasi-public knowledge and the lower is the actual output of the knowledge generation activities. With a given budget firms that enjoy relevant knowledge externalities can take advantage of access costs to the stock of quasi-public knowledge that are below equilibrium levels and can generate a larger amount of knowledge at costs that are below equilibrium levels;

3 ) the larger the knowledge output and the lower its costs and the larger the output $\mathrm{Y}$ of the technology production function and the levels of total factor productivity. 
The dynamics of the system, for given and invariant levels of the quality of knowledge governance mechanisms, exhibits the typical traits of a self-sustained process supported by positive feed-backs:

4) because of the working of diachronic knowledge externalities according to which the flows of proprietary knowledge add on to the stock of quasi-public knowledge, after a limited time window of appropriation, the larger the knowledge output at each point in time, and, for invariant levels of knowledge governance, the larger the stock of quasi-public knowledge hence lower its costs and consequently the lower are knowledge costs and higher are the chances that firms are able to implement an effective creative response;

5) the higher the rates of introduction of innovations and the larger the growth of total factor productivity and the larger are likely to be the unexpected changes in factor and product markets that are at the origin of out-of-equilibrium conditions levels of variety within the system. Variety and heterogeneity are more likely to be persistent and actually may amplify in systems characterized by fast rates of introduction of innovation. A virtuous self-feeding process of creative disorder can actually enter in place, provided the quality of knowledge governance mechanisms is also persistent.

6) the lower the rates of introduction of innovation, due the low quality of knowledge governance mechanisms and hence the slow rates of accumulation of the stock of quasi-public knowledge and the high access costs to it, and the lower the chances that creative response actually can take place. The prevalence of adaptive responses reduces the heterogeneity of firms. The typical Marshallian search for equilibrium displays fully its effects: least performing firms are sorted out and the benchmark quality of outstanding ones is rapidly imitated by all the other firms. At the end of the Marshallian process heterogeneity is substituted by homogeneity and equilibrium conditions prevail.

The quality of knowledge governance mechanisms is fragile and fully exposed to events that may take place along the process and change it. The generation of new technological knowledge and the introduction of new technologies, at each point in time, can change, even radically, the structure of the system, the organization of knowledge interactions and transactions, the architecture of knowledge networks and the institutional setting that qualify the knowledge governance mechanisms.

The dynamics of the system, consequently, is path dependent, as opposed to past-dependent as it exhibits strong historic, non ergodic elements, such as the size of the stock of quasi-public knowledge that depend upon the accumulation of the flows of generation, and at the same time it is exposed to the possible degeneration of the quality of knowledge governance mechanisms brought about the very dynamics of the process. 
The decline of the quality of knowledge governance mechanisms can easily stop the dynamics of the system with two distinct negative effects: i) it reduces the rates of accumulation of the flows of new technological knowledge and hence the increase of the size of the stock of quasi-public knowledge. This has direct negative effects on the rates of reduction of the access costs of external knowledge that firms use as a necessary complementary input in the recombinant generation of new technological knowledge; ii) it increases the levels of absorption costs and consequently may actually lead to an increase of the cost of external knowledge. The consequences are clear. The likelihood that firms cam implement creative, rather, than adaptive, response declines with the consequent reduction of the rates of technological change and increase of total factor productivity.

Figure 3. The dynamics of the creative response

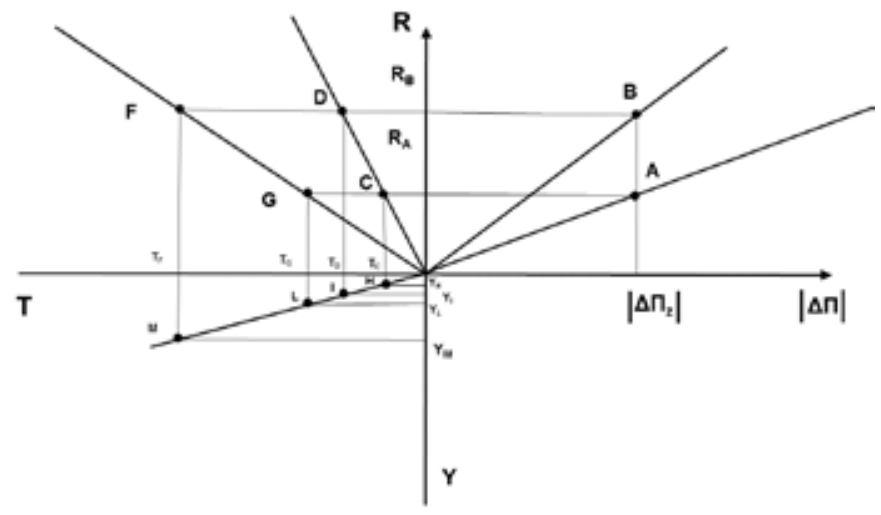

\section{Conclusions}

The notion of creative response is at the same time the synthesis of the Schumpeterian legacy and the founding stone of a comprehensive platform that uses the tools of evolutionary complexity able to accommodate in a coherent framework the understanding of endogenous innovation as an emergent system property. The notion of creative response enables to go beyond the limitations and shortcomings of the evolutionary approaches that build upon biological metaphors. Innovation can be analyzed as the outcome of the interdependence between individual decision-making and the properties of the system into which it takes place. The outcome of individual decision-making -the actual introduction of innovations- depends upon the characteristics of the system. The latter in turn is influenced by the outcomes of individual decision-making. 
This essay has explored the engines of the creative response: the levels of reactivity of firms to out-of-equilibrium conditions and the properties of the system that support the creative response with the provision of knowledge externalities that enable innovating firms to access and use the stock of quasi-public knowledge to generate new knowledge at costs that are below equilibrium levels.

The analysis has shown that low levels of reactivity reduce the amount of innovative efforts a system is able to mobilize. At the same time high levels of reactivity without the support of appropriate levels of knowledge governance favor the rapid return to equilibrium levels, but not the actual introduction of innovations. High quality knowledge governance mechanisms coupled with low levels of reactivity lead to slow rates of introduction of innovations and slow rates of increase of output and total factor productivity. On the opposite, a system characterized by high levels of reactivity and high levels of knowledge governance enable firms to implement a creative response that leads to fast rates of introduction of innovation, increase of output and of total factor productivity.

Systems characterized by high quality and persistent knowledge governance mechanisms and reactive managerial styles are likely to experience fast rates of introduction of innovations that feed persistent growth via: $i$ ) the re-creation of out-of-equilibrium conditions, $i$ ) the accumulation of the stock of quasi-public knowledge, iii) the quality of knowledge governance mechanisms, iv) the persistence of knowledge externalities. In such system the creative disorder is persistent and may last as long as the quality of knowledge governance mechanisms is able to cope with the dynamics of the system and is fortified rather than damaged by it. An endogenous loop of positive feedbacks supports the growth of the system and the persistence of out-of-equilibrium conditions.

Systems characterized by low quality knowledge governance mechanisms are managerial styles with low levels of reactivity are doomed to converge rapidly to equilibrium. The Marshallian search for equilibrium prevails when adaptive response prevails on the creative one. The adaptive response prevails when the quality of knowledge governance mechanisms is poor, and consequently the amount of knowledge generated at each point in time is small and cumulates with slow rates, the access and secondary use costs of the stock of quasi-public knowledge are high, search activities enable to engage in technical rather than technological changes. The variance of firms is quickly reduced by the exit of least performing firms and the imitation of advanced ones. Variety decreases together with variance and the slow down of the rates of innovation, the rates of increase of total factor productivity and the growth of output.

The implications for economic policy are clear. First, a managerial style able to integrate high levels of entrepreneurship helps increasing the performance of a 
system. The dichotomy between entrepreneurs and managers, where the former are associated with small firms and start-ups and the latter with incumbent corporations should be abandoned. Creative managers of large corporations are necessary as much as competent entrepreneurs in small firms and newcomers. Second, the quality of the knowledge governance mechanisms that rule the accumulation of the stock of quasi-public knowledge and its access and secondary use at low costs is a central asset of an economic system that assigns to the rate of introduction of technological and organizational innovations a central role.

Public policy should care about the architecture of the inter-sectorial flows of knowledge along the multi-stage user-producer interactions, the quality of the public research infrastructure, the interface between public and private research centers, the mobility of skilled personnel both among firms and between firms and the public research system, the working of the knowledge markets, the role of knowledge-intensive-business-services, the exclusivity of intellectual property rights so as to favor at the same time the appropriation of the economic benefits stemming from the introduction of innovations and yet the useful dissemination and secondary uses of existing technological knowledge.

\section{APPENDiX. A SIMPLe MODEL}

Following the literature that impinges upon the CDM approach (Crépon, Duguet, Mairesse, 1998), the analysis of the engines of the creative response can be framed into a simple system of equations: $i$ ) the research function; $i i)$ the knowledge generation function and its cost equation; iii) the external knowledge cost equation; iv) the technology production function. Let us introduce them in turn.

The research function summarizes the relationship between out-of-equilibrium conditions as measured by $\Delta \Pi$ i.e. the difference between the levels of profitability and performances of each firm and normal ones in absolute terms, i.e. taking into account both profits and performances above the norm and below it:

(1) $R=f(j \Delta \Pi)$

where $\mathrm{j}$ measures the levels of reactivity.

The knowledge generation function formalizes the relationship between research efforts (R) and the actual output of knowledge (T) taking into account the stock of quasi-public knowledge (SQPT) available in the system, where $\mathrm{m}$ and $\mathrm{n}$ are their output elasticity. The Cobb-Douglas specification of the knowledge generation function makes explicit the strict complementarity between the stock of 
external knowledge drawn from the stock of quasi-public knowledge available in the system and the flow of internal research efforts. The cost equation includes on the left hand side the amount $\mathrm{R}$ of the research budget that has been determined by equation (1) and, on the right hand side, the unit costs (r) of research and development activities $(R \& D)$ and the search costs $(u)$ that enable to access and use of the stock of quasi-public knowledge:

(2) $\mathrm{T}=\mathrm{h}\left(\mathrm{R}^{\mathrm{m}} \mathrm{SQPA}^{\mathrm{n}}\right)$

(3) $R=r R \& D+u S P Q T$

The size of the stock of quasi-public knowledge is fully endogenous. Because of diachronic knowledge externalities, in fact, it depends on the amount of knowledge flows that have been generated in previous time periods and the quality of knowledge governance mechanisms that rule their accumulation process:

(4) $S Q P T=l\left(K G M,\left(\sum_{t=n}^{N} T_{t}\right)\right)$

The costs of accessing and using the stock of quasi-public knowledge also are endogenous as they depends on its own size (SSPQT) and the quality of knowledge governance mechanisms (KGM):

(5) $\mathrm{u}=\mathrm{m}($ SSPQT, KGM), where h'<0

The unit cost of technological knowledge (z) is now fully endogenous:

(6) $z=R / T$

Finally, the technology production function specifies the relationship between output $\mathrm{Y}$, the standard inputs capital $(\mathrm{K})$ and labor $(\mathrm{L})$ and knowledge $(\mathrm{T})$ produced in the upstream knowledge generation function, with their respective output elasticity $\alpha, \beta$, and $\gamma$. Next to it, the standard cost equation where $\mathrm{r}$ measures capital user costs, $w$ wages and $\mathrm{z}$ the actual level of the cost of knowledge generated upstream that takes into account the effects of knowledge externalities. Equation (7) includes the measure (A) of total factor productivity:
(7) $\mathrm{Y}=\mathrm{A}\left(\mathrm{K}^{\alpha} \mathrm{L}^{\beta} \mathrm{T}^{\gamma}\right)$
(8) $\mathrm{C}=\mathrm{rK}+\mathrm{wl}+\mathrm{zT}$ 
Because $\mathrm{zT}=\mathrm{R}$, it is evident that, for endogenous levels of $\mathrm{R}$, the lower are the endogenous levels of $\mathrm{z}$ and the larger is T. Hence the levels of total factor productivity are determined by the difference between the equilibrium levels of the cost of knowledge (g) that would take place if it were a standard economic good and the actual costs of knowledge (z) that take into account the effects of upstream knowledge externalities:

(9) $A=n(g-z)$

When $\mathrm{z}=\mathrm{g}$ firms are not able to introduce productivity enhancing innovations. The introduction of productivity enhancing innovations takes place only when $\mathrm{g}>\mathrm{z}$, when the generation of technological knowledge can rely upon effective knowledge externalities that reduce the cost of external knowledge $(\mathrm{u})$ below equilibrium levels so that also the costs of technological knowledge (z) as an intermediary and yet indispensable input in the technology production function are below the equilibrium levels g (Antonelli, 2013 and 2017).

\section{REFERENCES}

Acemoglu, D., Aghion, P., Bursztyn and L., Hémous, D. (2012), “The environment and directed technical change", American Economic Review, 102, 131-66. Aghion, P., Dechezlepretre, A., Hemous, D., Martin, R. and Van Reenen, J. (2016), "Carbon taxes, path dependency, and directed technical change: Evidence from the auto industry", Journal of Political Economy, 124, 52-104.

Antonelli, C. (2008), Localized technological change. Towards the economics of complexity, Routledge, London.

(ed.) (2011), Handbook on the economic complexity of technological change, Edward Elgar, Cheltenham.

(2013), "Knowledge governance, pecuniary knowledge externalities and total factor productivity growth", Economic Development Quarterly, 27, 62-70.

(2015a), "Innovation as a creative response. A reappraisal of the Schumpeterian legacy", History of Economic Ideas, 23, 99-118.

(2015b), "The dynamics of knowledge governance", in Antonelli, C., Link, A. (eds.) Handbook on the economics of knowledge, Routledge, London, 232-262.

(2017), Endogenous innovation: The economics of an emergent system property, Edward Elgar, Cheltenham. 
Arrow, K. J. (1962), "Economic welfare and the allocation of resources for invention", in Nelson, R. R. (ed.), The rate and direction of inventive activity: Economic and social factors. Princeton University Press for N.B.E.R., Princeton, 609-625.

Arthur, B. (2007), "Complexity and the economy”, in Hanusch, H., Pyka, A. (eds.), Elgar companion to Neo-Schumpeterian economics, Edward Elgar, Cheltenham.

(2015), Complexity and the Economy, Oxford, Oxford University Press.

Arthur, W. B. (2009), The nature of technology. What it is and how it evolves. Free Press, New York.

Arthur, W. B., Durlauf, S.N. and Lane, D.A. (eds.) (1997), The economy as an evolving complex system II, Addison-Wesley, Redwood City, CA.

Crépon, B., Duguet, E. and Mairesse, J. (1998), "Research and development, innovation and productivity: An econometric analysis at the firm level", Economics of Innovation and New Technology, 7 (2), 115-58.

Dasgupta, P. and Stiglitz, J. (1980), "Industrial structure and the nature of innovative activity", Economic Journal, 90, 266-293.

Foster J., Metcalfe J. S. (2012), "Economic emergence: An evolutionary economic perspective", Journal of Economic Behavior and Organization, 82 (2), 420-432.

Griliches, Z. (1979), "Issues in assessing the contribution of research and development to productivity growth", Bell Journal of Economics, 10 (1), 92-116.

Metcalfe, J. S. (1998), Evolutionary economics and creative destruction, Routledge, London.

Nelson, R. R. and Winter S. G. (1982), An evolutionary theory of economic change, Cambridge, The Belknap Press of Harvard University Press.

Newell, R. G., Jaffe, A. B. and Stavins, R. N. (1999), "The induced innovation hypothesis and energy-saving technological change", Quarterly Journal of Economics, 114, 941-975.

Ostrom, E. and Hess, C. (eds.) (2006), Understanding knowledge as a commons: From theory to practice, MIT Press, Cambridge.

Page, S. E. (2011), Diversity and complexity, Princeton University Press, Princeton.

Porter, M. E. and van der Linde, C. (1995), "Toward a new conception of the environment-competitiveness relationship", Journal of Economic Perspectives, 9, 97-118.

Scherer, F. M. (1986), Innovation and growth: Schumpeterian perspectives, MIT Press, Cambridge. 
Schumpeter, J. A. (1911, 1934), The theory of economic development, Harvard University Press, Cambridge.

(1939), Business cycles. A theoretical, historical and statistical analysis of the capitalist process, McGraw-Hill, New York. (1942), Capitalism socialism and democracy, Harper and Brothers, New York.

(1947), "The creative response in economic history", Journal of Economic History, 7, 149-159.

Simon, H. A. (1947), Administrative Behavior: A Study of Decision-Making Processes in Administrative Organization, London, Macmillan. (1979), "Rational decision making in business organizations", American Economic Review, 69 (4), 493-513. (1982), Metaphors of Bounded Rationality: Behavioral Economics and Business Organization, Cambridge, MA, MIT Press.

Weitzman, M. L. (1996), "Hybridizing growth theory", American Economic Review, 86, 207-212. 